\title{
UJI EFISIENSI TUNGKU ROKET BERBAHAN BATA RINGAN
}

\author{
Tabah Priangkoso, Arif Rahman Salim, Darmanto \\ Jurusan Teknik Mesin, Fakultas Teknik, Universitas Wahid Hasyim \\ Jl. Menoreh Tengah X/22, Sampangan, Semarang 50236. \\ *Email: tabah@unwahas.ac.id
}

\begin{abstract}
Abstrak
Tungku konvensional berbahan bakar kayu memiliki efisiensi yang sangat rendah sebesar 5 $10 \%$. Selain rendah efisiensinya, penggunaan tungku konvensional juga menyebabkan paparan asap yang berbahaya bagi penggunanya. Tungku roket dengan bahan bata ringan menjadi alternatif untuk meningkatkan efisiensi dan menghindarkan paparan asap. Penelitian ini bertujuan menguji efisiensi tungku roket berbahan bata ringan dengan tinggi tungku 0,4; 0,5; dan 0,6 m. Efisiensi tertinggi rata-rata diperoleh dari penggunaan tungku tinggi 0,6 m sebesar 24\%, lebih tinggi dibanding tungku beton maupun tungku sekam. Tungku bata ringan menghindarkan paparan asap bagi penggunanya dan relatif selamat bagi penggunanya dari panas dinding tungku karena temperatur maksimum yang dicapai hanya $60^{\circ} \mathrm{C}$. Dari sisi harga, tungku bata ringan jauh lebih murah dibanding tungku beton.
\end{abstract}

Kata kunci: tungku roket, bata ringan, efisiensi

\section{PENDAHULUAN}

Sampai dengan 2014, terdapat 24 juta keluarga di Indonesia masih menggunakan tungku konvensional dengan bahan bakar kayu untuk untuk memasak. Penggunaan tungku ini juga menyebabkan kematian dini 165 ribu jiwa akibat terpapar asap pembakaran dari tungku (Ferial, 2014). Selain itu, tungku konvensional juga memiliki efisiensi yang sangat rendah, sebesar 5-10\% (Nurhuda, 2011).

Untuk meningkatkan efisiensi penggunaan kayu pada tungku dan mengurangi paparan asap pembakaran pada penggunaan tungku konvensional, dirancang tungku roket dengan bahan bata ringan. Desain tungku roket dipilih karena tungku jenis ini memiliki efisiensi yang cukup tinggi dan menghemat sampai $75-90 \%$ kayu bakar atau empat kali lebih efisien dibanding tungku konvensional. Selain itu, tungku roket juga dapat mengurangi paparan asap lebih dari 90\% (Anonimous, 2018).

Bata ringan dipilih sebagai bahan tungku karena ringan dan memiliki konduktivitas termal yang rendah dibanding beton sebagaimana tersaji pada Tabel 1. Selain itu, bata ringan mudah diperoleh, dipindahkan, dan dipotong sesuai kebutuhan. Dimensi standar bata ringan yang digunakan untuk tungku adalah $0,60 \times 0,20 \times 0,10 \mathrm{~m}$.

Konduktivitas yang rendah memberikan keuntungan dalam efisiensi karena menghambat perpindahan kalor dari api ke lingkungan. Selain itu, dinding luar tungku terhindar dari temperatur tinggi, sehingga lebih selamat dibanding dinding yang terbuat dari beton.

Tabel 1 Perbandingan densitas dan konduktivitas termal antara bata ringan dengan beton

\begin{tabular}{llr}
\multicolumn{1}{c}{ Bahan } & Densitas & $\begin{array}{c}\text { Konduktivitas } \\
\text { termal }\end{array}$ \\
\hline Bata Ringan $^{1}$ & $520 \mathrm{~kg} / \mathrm{m}^{3}$ & $0,16 \mathrm{~W} / \mathrm{m} \mathrm{K}$ \\
Beton $^{2}$ & $2200 \mathrm{~kg} / \mathrm{m}^{3}$ & $1,40 \mathrm{~W} / \mathrm{m} \mathrm{K}$ \\
\hline${ }^{1}$ www.hebel.co.id & \\
${ }^{2}$ Irvine, 1998 & &
\end{tabular}

Penelitian ini bertujuan untuk menguji efisiensi tungku roket berbahan bata ringan dengan variasi tinggi tungku 0,$4 ; 0,5$; dan $0,6 \mathrm{~m}$ untuk memperoleh tingkat efisiensi tertinggi di antara ketiganya. Temperatur dinding luar juga diukur untuk menentukan tingkat keselamatan pengguna dari paparan panas.

\section{METODE \\ Pembuatan tungku}

Tungku roket berbahan bata ringan didesain berbentuk susunan bata ringan dengan ukuran tapak $0,4 \times 0,7 \mathrm{~m}$ dan lubang tungku $0,2 \times 0,2$ $\mathrm{m}$ dengan variasi tinggi tungku 0,$4 ; 0,5 ;$ dan 0,6 $\mathrm{m}$. Pembuatan tungku dilakukan dengan menyusun bata ringan menjadi tungku dengan langkah-langkah sebagaimana ditunjukkan pada Gambar 1 sebagai berikut:

1. Menyusun bata ringan paling bawahmenggunakan 3 buah bata ringan. Untuk dinding bagian belakang, bata 
ringan yang semula mempunyai panjang $0,6 \mathrm{~m}$ dipotong menjadi $0,4 \mathrm{~m}$. Untuk dinding sisi kanan dan kiri tetap menggunakan bata ringan utuh;

2. Pada lapis ke dua, dinding belakang memiliki ukuran yang sama dengan dinding di bawahnya, yaitu bata ringan yang mempunyai panjang $0,6 \mathrm{~m}$ dipotong menjadi $0,4 \mathrm{~m}$;

3. Untuk dinding kanan dan kiri lapis kedua bata ringan yang dipotong menjadi $0,2 \mathrm{~m}$;

4. Bagian dinding depan lapis ke dua bata ringan dengan ukuran yang sama dengan dinding belakang, yaitu $0,4 \mathrm{~cm}$;

5. Bagian depan kemudian ditutup dengan bata ringan ukuran panjang $0,4 \mathrm{~cm}$ sebagai tempat pemasukan kayu.

6. Untuk tinggi tungku $0,5 \mathrm{~m}$, ditambahkan lapis ketiga bata ringan yang telah dipotong sehingga menambah tinggi dari $0,4 \mathrm{~m}$ menjadi $0,5 \mathrm{~m}$. Demikian juga untuk tinggi tungku $0,6 \mathrm{~m}$. Untuk mengurangi atau mencegah paparan asap di sekitar tungku, dipasang cerobong yang menghubungkan tungku dengan udara luar.

Pada bagian bawah (dasar) tungku, dipasang rak besi setinggi $0,05 \mathrm{~m}$ agar kayu tidak bersentuhan dengan lantai atau tanah, untuk memudahkan memisahkan abu dari kayu dan melancarkan aliran udara dari luar ke dalam tungku.

Tungku disusun tanpa menggunakan perekat sehingga mudah dilepas dan dipindahkan. Meskipun tanpa perekat, celah antar bata ringan tidak terlihat. Hal ini memperkecil kemungkinan kalor keluar melalui celah-celah antar bata ringan.

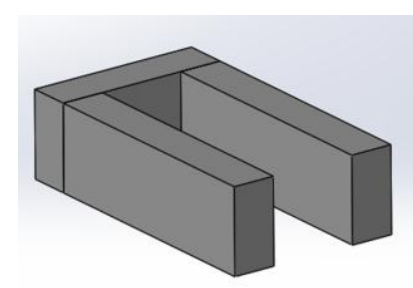

(1)

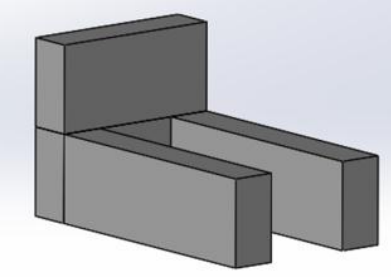

(2)

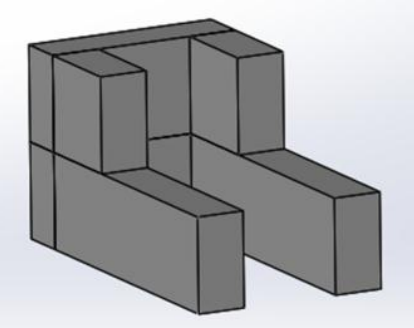

(3)

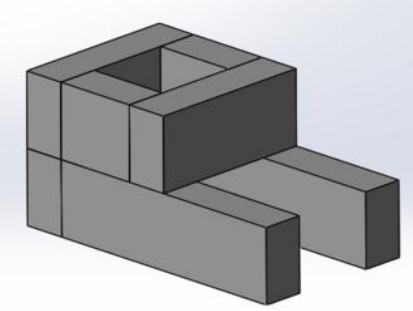

(4)

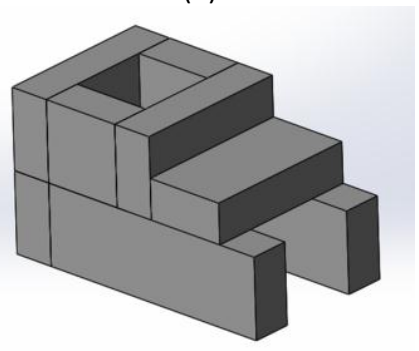

(5)

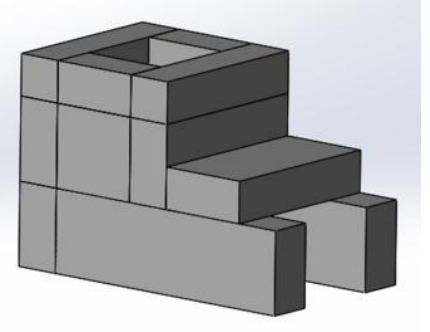

(6)

Gambar I Langkan-langkan menyusun bata ringan menjadi tungku 
Pengujian efisiensi dilakukan dengan cara membandingkan energi yang diterima air yang direbus di atas tungku dengan jumlah energi kayu yang digunakan sebagai bahan bakar. Efisiensi tungku dihitung berdasarkan

$$
\eta=\frac{Q_{t}}{Q_{k}} \times 100 \%
$$

dimana

$Q_{t}=$ jumlah energi yang diberikan tungku, kJ $Q_{k}=$ jumlah energi kayu, $\mathrm{kJ}$

Jumlah energi yang diterima air dihitung berdasarkan kenaikan temperatur air yang dipanaskan di atas tungku

$$
Q_{a}=m_{a} c_{a} \Delta T_{a}
$$

dimana

$m_{a}=$ massa air, $\mathrm{kg}$

$c_{a}=$ kapasitas panas spesifik air, $4,19 \mathrm{~kJ} / \mathrm{kg} \mathrm{K}$

$\Delta T_{a}=$ kenaikan temperatur air, $\mathrm{K}$

Jumlah energi kayu dihitung berdasarkan

$$
Q_{k}=m_{k} L H V_{k}
$$

dimana

$m_{k}=$ massa kayu, $\mathrm{kg}$

$L H V_{k}=$ nilai kalor terendah kayu, $14.400 \mathrm{~kJ} / \mathrm{kg}$

(Krajnc, 2015)

\section{Rancangan Percobaan}

Percobaan dilakukan dengan merebus 10 liter air di dalam panci alumunium diameter 0,25 mdan tinggi $0,25 \mathrm{~m}$ yang diletakkan di atas tungku dengan tinggi tungku $0,40 \mathrm{~m} ; 0,50 \mathrm{~m}$; dan 0,60 m masing-masing 5 kali perebusan. Kayu campuran sebanyak $1,0 \mathrm{~kg}$ digunakan sebagai bahan bakar dalam sekali perebusan.

Temperatur air diukur sebelum direbus dan selama perebusan untuk menentukan temperatur tertinggi menggunakan termometer alkohol, sedangkanwaktu pencapaian temperatur tertinggi air selama direbus, diukur menggunakan stopwatch. Pengukuran waktu diperlukan karena kalor dari tungku tidak hanya digunakan untuk memanaskan air, tetapi juga memanaskan panci. Di sisi lain, panci juga melepas kalor ke lingkungan, sehingga kalor ini harus dimasukkan dalam perhitungan efisiensi tungku.
Temperatur dinding luar panci diukur untuk menentukan jumlah kalor yang keluar selama perebusan air menggunakan termometer infra merah untuk menentukan kalor konveksi dan radiasi yang dilepas ke lingkungan.

Dinding luar yang paling dekat dengan api diukur temperaturnya menggunakan termometer infra merah untuk melihat apakah temperaturnya berbahaya atau tidak bagi pengguna tungku.

Kalor yang dilepas oleh panci dihitung menggunakan persamaan

$$
\dot{q}_{p}=\dot{q}_{c}+\dot{q}_{r}
$$

dimana

$\dot{q}_{p}=$ kalor yang dilepas oleh panci, $\mathrm{W}$

$\dot{q}_{c}=$ kalor konveksi dinding panci ke udara, $\mathrm{W}$

$\dot{q}_{r}=$ kalor radiasi dinding panci ke lingkungan, $\mathrm{W}$

Kalor konveksi yang dilepas dinding panci ke udara sebesar

$$
\dot{q}_{c}=h A\left(T_{p}-T_{\infty}\right)
$$

dimana

$h=$ koefisien perpindahan kalor konveksi, $25 \mathrm{~W} / \mathrm{m}^{2} \mathrm{~K}$ (Cengel, 2003)

$A=$ luas permukaan dinding luar panci, $0,012 \mathrm{~m}^{2}$

$T_{p}=$ temperatur dinding luar panci, $\mathrm{K}$

$T_{\infty}=$ temperatur lingkungan, $\mathrm{K}$

Kalor radiasi yang dilepas dinding panci ke lingkungan sebesar

$$
\dot{q}_{r}=\sigma \varepsilon A\left(T_{p}^{4}-T_{\infty}^{4}\right)
$$

dimana

$\sigma=$ konstanta Stefan-Boltzmann;

$$
5,67 \times 10^{-8} \mathrm{~W} / \mathrm{m}^{2} \mathrm{~K}^{4}
$$

$\varepsilon=$ emisivitas dinding panci alumunium; 0,03 (Cengel, 2003)

$A=$ luas permukaan dinding luar panci, $0,012 \mathrm{~m}^{2}$

$T_{p}=$ temperatur dinding luar panci, $\mathrm{K}$

$T_{\infty}=$ temperatur lingkungan, $\mathrm{K}$

Total kalor yang dapat diberikan oleh tungku sebesar

$$
Q_{t}=Q_{a}+Q_{p}
$$


Total energi yang diberikan ke lingkungan oleh dinding panci adalah

$$
Q_{p}=\dot{q}_{p} t
$$

dimana

$t=$ waktu perebusan, $\mathrm{s}$

\section{HASIL DAN PEMBAHASAN}

Laju aliran kalor yang diberikan oleh tungku kepada panci sebagian dibuang ke lingkungan dari dinding luar panci dalam bentuk konveksi dan radiasi. Kalor ini diperhitungkan dalam efisiensi karena mengurangi jumlah energi yang diserap oleh air yang direbus. Alasan lainnya adalah temperatur lingkungan pada saat dilakukan perebusan air tidak sama, sehingga jumlah kalor yang dilepas ke lingkungan oleh panci juga tidak sama. Semakin rendah temperatur lingkungan, maka semakin besar laju perpindahan kalor ke lingkungan.

Laju kalor radiasi $\dot{q}_{r}$ dapat dianggap tidak berpengaruh terhadap jumlah total kalor yang dilepas ke lingkungan karena jumlahnya yang sangat kecil dibandingkan dengan laju kalor konveksi $\dot{q}_{c}$, sebagaimana ditunjukkan Tabel 2.

Tabel 2 Laju aliran kalor dari dinding luar panci ke lingkungan

\begin{tabular}{ccccccc}
\hline No & $\begin{array}{c}\text { Tinggi } \\
\text { tungku }(\mathrm{m})\end{array}$ & $\begin{array}{c}T_{\infty} \\
(\mathrm{K})\end{array}$ & $\begin{array}{c}T_{p} \\
(\mathrm{~K})\end{array}$ & $\begin{array}{c}\dot{q}_{c} \\
(\mathrm{~W})\end{array}$ & $\begin{array}{c}\dot{q}_{r} \\
(\mathrm{~W})\end{array}$ & $\begin{array}{c}\dot{q}_{p} \\
(\mathrm{~W})\end{array}$ \\
\hline 1 & 0,40 & 300 & 310,7 & 339,6 & 0,00428 & 339,6 \\
2 & & & 313,1 & 417,8 & 0,00594 & 417,8 \\
3 & & & 320,9 & 664,9 & 0,01363 & 664,9 \\
4 & & & 317,5 & 558,1 & 0,00981 & 558,1 \\
5 & & & 320,2 & 642,6 & 0,01276 & 642,6 \\
\hline 1 & 0,50 & 302 & 311,0 & 287,0 & 0,00399 & 287 \\
2 & & & 314,3 & 392,3 & 0,00637 & 392,3 \\
3 & & & 313,7 & 373,1 & 0,00589 & 373,1 \\
4 & & & 309,9 & 250,3 & 0,00329 & 250,3 \\
5 & & & 322,0 & 636,2 & 0,01456 & 636,2 \\
\hline 1 & 0,60 & 298 & 310,6 & 1199,1 & 0,00578 & 1199,1 \\
2 & & & 317,3 & 1411,2 & 0,01109 & 1411,2 \\
3 & & & 317,2 & 1409,6 & 0,01104 & 1409,6 \\
4 & & & 317,3 & 1412,8 & 0,01114 & 1412,8 \\
5 & & & 314,7 & 1328,2 & 0,00871 & 1328,3 \\
\hline
\end{tabular}

Dengan demikian, secara praktis kalor radiasi dapat diabaikan dalam perhitungan efisiensi tungku, sehingga $\dot{q}_{p}=\dot{q}_{c}$.

Pada Tabel 3 dapat dilihat bahwa rata-rata efisiensi tungku dengan tinggi $0,40 \mathrm{~m}$ sebesar rata-rata $16,7 \%$. Dibanding dengan tungku beton cor dengan insulasi udara pada dinding tungku yang memiliki efisiensi terendah $16 \%$ (Yunianto, Sinaga, \& Ramanda, 2014), tungku roket ini memiliki efisiensi yang sama. Namun demikian, tungku ini efisiensinya lebih rendah dibanding efisiensi tertinggi tungku beton sebesar 20\% (Yunianto, Sinaga, \& Ramanda, 2014).

Tabel 3 Hasil pengujian tungku setinggi $0,40 \mathrm{~m}$ dengan temperatur lingkungan $300 \mathrm{~K}$

\begin{tabular}{ccccccc}
\hline No & $\begin{array}{c}\Delta T_{a} \\
(\mathrm{~K})\end{array}$ & $\begin{array}{c}t \\
(\mathrm{~s})\end{array}$ & $\begin{array}{c}Q_{a} \\
(\mathrm{~kJ})\end{array}$ & $\begin{array}{c}Q_{p} \\
(\mathrm{~kJ})\end{array}$ & $\begin{array}{c}Q_{t} \\
(\mathrm{~kJ})\end{array}$ & $\begin{array}{c}\eta \\
(\%)\end{array}$ \\
\hline 1 & 45,6 & 1455 & 1910,6 & 494,2 & 2404,8 & 16,7 \\
2 & 42,1 & 1316 & 1764,0 & 549,8 & 2313,8 & 16,1 \\
3 & 43,5 & 1182 & 1822,7 & 786 & 2608,6 & 18,1 \\
4 & 37,6 & 951 & 1575,4 & 530,7 & 2106,2 & 14,6 \\
5 & 48,6 & 897 & 2036,3 & 576,4 & 2612,8 & 18,1 \\
\hline $\begin{array}{c}\text { Rata- } \\
\text { rata }\end{array}$ & 43,5 & 1160,2 & 1821,8 & 587,4 & 2409,2 & 16,7 \\
\hline
\end{tabular}

Tungku dengan tinggi $0,50 \mathrm{~m}$ memiliki efisiensi lebih baik sebesar rata-rata $18,1 \%$ seperti disajikan pada Tabel 4. Hasil ini masuk dalam kisaran efisiensi tungku beton.

Tabel 4Hasil pengujian tungku setinggi $0,50 \mathrm{~m}$ dengan temperatur lingkungan $302 \mathrm{~K}$

\begin{tabular}{ccccccc}
\hline No & $\begin{array}{c}\Delta T_{a} \\
(\mathrm{~K})\end{array}$ & $\begin{array}{c}t \\
(\mathrm{~s})\end{array}$ & $\begin{array}{c}Q_{a} \\
(\mathrm{~kJ})\end{array}$ & $\begin{array}{c}Q_{p} \\
(\mathrm{~kJ})\end{array}$ & $\begin{array}{c}Q_{t} \\
(\mathrm{~kJ})\end{array}$ & $\begin{array}{c}\eta \\
(\%)\end{array}$ \\
\hline 1 & 52,7 & 1397 & 2208,1 & 401 & 2609,1 & 18,1 \\
2 & 46,7 & 1143 & 1956,7 & 448,4 & 2405,1 & 16,7 \\
3 & 45 & 1181 & 1885,5 & 440,7 & 2326,2 & 16,2 \\
4 & 47,6 & 1662 & 1994,4 & 416,1 & 2410,5 & 16,7 \\
5 & 55,5 & 1474 & 2325,5 & 937,8 & 3263,3 & 22,7 \\
\hline $\begin{array}{l}\text { Rata- } \\
\text { rata }\end{array}$ & 49,5 & 1371,4 & 2074,1 & 528,8 & 2602,8 & 18,1 \\
\hline
\end{tabular}

Kenaikan temperatur air $\Delta T_{a}$ yang bisa dicapai sebesar 49,5 K. Lebih tinggi dibanding tungku dengan tinggi $0,40 \mathrm{~m}$ sebesar $43,5 \mathrm{~K}$. Peningkatan temperatur air pada tungku $0,50 \mathrm{~m}$ sebesar 49,5 K lebih tinggi dibanding yang dicapai tungku $0,40 \mathrm{~m}$. Hal ini disebabkan temperatur lingkungan lebih tinggi pada saat perebusan air dilakukan menggunakan tungku $0,50 \mathrm{~m}$.

Selisih temperatur dinding luar panci dengan lingkungan rata-rata saat perebusan air menggunakan tungku $0,50 \mathrm{~m}$ adalah $12,2 \mathrm{~K}$ dibanding tungku $0,40 \mathrm{~m}$ sebesar $16,5 \mathrm{~K}$. Semakin besar perbedaan temperatur dinding panci dengan lingkungan, akan semakin besar laju perpindahan kalor dari dinding luar panci ke lingkungan. Hal ini menyebabkan kalor yang diterima air dialirkan keluar panci sehingga peningkatan temperatur air terhambat.

Jika dilihat pada Tabel 5, perebusan air menggunakan tungku setinggi 0,60 mpeningkatan temperatur air paling 
rendahsebesar 34,5 $\mathrm{K}$, tetapi kalor yang dibuang ke lingkungan paling tinggi karena perbedaan temperatur dinding luar panci dan lingkungan juga paling besar, yaitu 17,4 K.

Dengan memperhitungkan kalor yang dibuang ke lingkungan melalui panci, efisiensi tertinggi dimiliki oleh tungku dengan tinggi $0,60 \mathrm{~m}$, yaitu sebesar $24,0 \%$ sebagaimana ditunjukkan pada Tabel 5. Angka ini lebih tinggi dari pada efisiensi tertinggi pada tungku beton. Hasil ini menunjukkan bahwa tungku roket bata ringan dengan tinggi tungku $0,60 \mathrm{~m}$ memiliki efisiensi lebih tinggi dibanding tungku beton. Hasil ini juga lebih tinggi dibanding tungku sekam sebesar 20,4\% (Suhandi, Rusdiana, \& Irzaman, 2013).

Tabel 5 Hasil pengujian tungku setinggi $0,60 \mathrm{~m}$ dengan temperatur lingkungan $298 \mathrm{~K}$

\begin{tabular}{ccccccc}
\hline No & $\begin{array}{c}\Delta T_{a} \\
(\mathrm{~K})\end{array}$ & $\begin{array}{c}t \\
(\mathrm{~s})\end{array}$ & $\begin{array}{c}Q_{a} \\
(\mathrm{~kJ})\end{array}$ & $\begin{array}{c}Q_{p} \\
(\mathrm{~kJ})\end{array}$ & $\begin{array}{c}Q_{t} \\
(\mathrm{~kJ})\end{array}$ & $\begin{array}{c}\eta \\
(\%)\end{array}$ \\
\hline 1 & 1265,4 & 873,0 & 1265,4 & 1046,8 & 2312,2 & 16,1 \\
2 & 1487,5 & 1760,0 & 1487,5 & 2483,7 & 3971,1 & 27,6 \\
3 & 1684,4 & 1495,0 & 1684,4 & 2107,3 & 3791,7 & 26,3 \\
4 & 1466,5 & 1737,0 & 1466,5 & 2454,0 & 3920,5 & 27,2 \\
5 & 1328,2 & 1493,0 & 1328,2 & 1983,1 & 3311,3 & 23,0 \\
\hline $\begin{array}{c}\text { Rata- } \\
\text { rata }\end{array}$ & 34,5 & 873,0 & 1446,4 & 2015,0 & 3461,4 & 24,0 \\
\hline
\end{tabular}

Perbandingan efisiensi tungku dengan tinggi tungku yang berbeda disajikan pada Gambar 2.

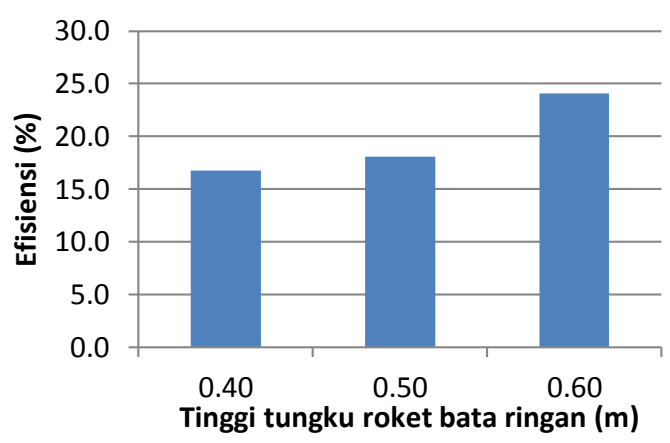

Gambar 2 Efisiensi tungku roket bata ringan

Dengan demikian, pilihan terbaik untuk desain tungku bata roket bata ringan adalah dengan tinggi $0,60 \mathrm{~m}$.

Tungku bata ringan ini mempunyai kelebihan pada kemudahan untuk dibuat, ringan, mudah dipindahkan, dan dapat langsung digunakan.

Dari sisi bobot, bata ringan jauh lebih ringan dibanding beton untuk ukuran yang sama. Dengan berpedoman pada Gambar 1, volume tungku untuk tinggi $0,60 \mathrm{~m}$ sebanyak $0,088 \mathrm{~m}^{3}$ sebagimana disajikan Tabel 6.

Tabel 6 Volume bata ringan untuk tungku tinggi 0,60 $\mathrm{m}$ berpedoman pada Gambar 1

\begin{tabular}{cccccc}
\hline \multicolumn{2}{c}{ Dimensi bata ringan $(\mathrm{m})$} & Jumlah & $\begin{array}{c}\text { Volume } \\
\left(\mathrm{m}^{3}\right)\end{array}$ \\
\cline { 1 - 3 } Panjang & Lebar & Tinggi & & 2 & 0,024 \\
0,60 & 0,20 & 0,10 & & 0,048 \\
0,40 & 0,20 & 0,10 & 6 & 0,016 \\
0,20 & 0,20 & 0,10 & 4 & 0,088 \\
\hline
\end{tabular}

Dengan ukuran volume yang sama, untuk tungku tinggi $0,60 \mathrm{~m}$, bata ringan memiliki bobot yang jauh lebih ringan yaitu $44,0 \mathrm{~kg}$ dibanding beton 193,6 kg.Dari sisi harga bahan baku, tungku bata ringan juga lebih murah dibanding beton. Untuk tungku $0,60 \mathrm{~m}$, tungku bata ringan memerlukan bahan baku seharga Rp130.000 dan beton Rp372.000. Perbandingan bobot dan harga bata ringan dengan beton disajikan pada Tabel 7.

Tabel 7 Perbandingan bobot dan harga tungku $0,60 \mathrm{~m}$ antara bata ringan dan beton

\begin{tabular}{lcc}
\hline \multicolumn{1}{c}{ Bahan } & Bobot $(\mathrm{kg})$ & Harga $(\mathrm{Rp})$ \\
\hline Bata ringan & 44,0 & 130.000 \\
Beton & 193,6 & 372.000 \\
\hline
\end{tabular}

Dengan konduktivitas termal yang lebih kecil (lihat Tabel 1), bata ringan relatif lebih selamat dari panas tungku dibanding beton karena bata ringan mampu menahan panas api lebih baik dari pada beton.

\section{KESIMPULAN}

Tungku roket bata ringan dengan tinggi 0,60 $\mathrm{m}$ berbahan bakar kayu memiliki efisiensi tertinggi sebesar 24,0\% dibanding tungku dengan tinggi $0,50 \mathrm{~m}$ dan $0,40 \mathrm{~m}$. Tungku ini juga jauh lebih ringan dan murah dibanding tungku beton dengan ukuran yang sama. Disamping itu, efisiensinya lebih tinggi dibandingkan tungku beton maupun tungku sekam.

\section{DAFTAR PUSTAKA}

Anonimous. (2018). Cookstoves. (Institutional Stove Solution) Diakses 03 April 2018, dari www.instove.org: http://www.instove.org/cookstoves

Cengel, Y. A. (2003). Heat Transfer: A Practical Approach. McGraw Hill.

Ferial. (2014, Agustus 14). Pemerintah Luncurkan Kompor Tungku Sehat. (Direktorat 
Jenderal Energi Baru Terbarukan dan

Konservasi Energi Kementerian ESDM)

Diakses 03 April 2018, dari

http://ebtke.esdm.go.id:

http://ebtke.esdm.go.id/post/2014/08/14/648/pe

merintah.luncurkan.kompor.tungku.sehat

Irvine, T. F. (1998). Thermophysical Properties. In W. M. Rohsenow, J. R. Hartnett, \& Y. I. Cho, Handbook of Heat Transfer (pp. 2.1-2.74). McGraw Hill.

Krajnc, N. (2015). Wood Fuel Handbook. Pristina: FAO.

Nurhuda, M. (2011). Kompor Biomass UB: Menuju Kemandirian . Mineral \& Energi , 9 (Desember).

Suhandi, A., Rusdiana, D., \& Irzaman. (2013). Kajian dan terapan konsep fisika dalam desain tungku sekam. Jurnal Pendidikan Fisika Indonesia , 184-190.

Yunianto, B., Sinaga, N., \& Ramanda. (2014). Pengembangan Desain Tungku Bahan Bakar Kayu Rendah Polusi dengan Menggunakan Dinding Beton Semen. Rotasi, $16(1), 28-33$. 